\title{
Age-gender differences in the postural sway during squat and stand-up movement
}

\author{
Ji-Won Kim ${ }^{\text {a }}$, Yuri Kwon ${ }^{\text {a }}$, Yeji Ho ${ }^{\text {a }}$, Hyeong-Min Jeon ${ }^{\mathrm{a}}$, Min-Jung Bang ${ }^{\mathrm{a}}$, \\ Jae -Hoon Jun ${ }^{\mathrm{a}, \mathrm{b}}$, Gwang-Moon Eom ${ }^{\mathrm{a}, \mathrm{b}, *}$, Byung Kyu Park ${ }^{\mathrm{c}, *}$ and Yeong Bin Cho ${ }^{\mathrm{d}}$ \\ ${ }^{a}$ School of Biomedical Engineering, Konkuk University, Choonju, 380-701, Korea \\ ${ }^{b}$ Research Institute of Biomedical Engineering, Konkuk University, Choonju, 380-701, Korea \\ ${ }^{c}$ Department of Physical Medicine \& Rehabilitation, Korea University College of Medicine, Seoul, \\ Korea \\ ${ }^{d}$ School of Business Administration and Economics, Konkuk University, Choonju, 380-701, Korea
}

\begin{abstract}
Incidence of falling among elderly female has been reported to be much higher than that of elderly male. Although the gender differences in the elderly were reported for the static postural sway, there has been no investigation of the gender difference for the dynamic postural sway. This study investigates how age and gender affect the postural sway during dynamic squat and stand-up movement. 124 subjects (62 subjects for each of young and elderly) performed consecutive squat and stand-up movement, 2 times in one session, and 2 sessions per subject. Center of pressure (COP) was measured using force platform during the test. Outcome measures included peak-to-peak sways of the COP (COP sway) in the sagittal plane (anteroposterior) and frontal plane (mediolateral) and also those normalized by body height. Two-way ANOVA and post-hoc comparisons were performed for the outcome measures with the independent factors of age and gender. All outcome measures, excluding mediolateral COP sway, showed significant interaction of age and gender $(\mathrm{p}<0.05)$. Post-hoc test revealed that only female showed increase in COP sway with age. When normalized by height, increase in COP sways (both directions) with age significant only in women resulted in greater sways in elderly female than elderly male. This may be related to the greater fall rate of elderly female than that of elderly men while performing dynamic activities.
\end{abstract}

Keywords: COP sway, dynamic activities, squat and stand-up, gender difference

\section{Introduction}

One third of old people ( 65 yrs or above) falls at least once in one year [1-3]. Recurrent falling worsens the quality of life and even results in mortality. Falls were reported to occur more among women than men for the old subjects. The fall ratio of old women was reported to be higher than that of old men (from 10 to 49\%) [4-6]. The control ability of postural balance was shown to predict falls [7-10]. If the postural control ability is different between genders, then it may associate with different fall ratios between genders.

\footnotetext{
${ }^{*}$ Corresponding authors: Gwang-Moon Eom, School of Biomedical Engineering, Konkuk University, Choonju, 380-701, Korea. Tel. +82-43-840-3766; Fax: +82-43-851-0620; E-mail: gmeom@kku.ac.kr.

Byung Kyu Park, Department of Physical Medicine \& Rehabilitation, Korea University College of Medicine, Seoul, 380701, Korea. Tel.: +82-31-412-4915; E-mail: caremotor@korea.ac.kr.
} 
Postural stability comprises static and dynamic ones, where these two were shown to be uncorrelated [11], indicating that they must be evaluated separately. Dynamic postural instability has been shown as an important risk factor of falling. Bergland and Wyller showed that inability of transfer task (to rise from the floor) was a significant risk factor of serious injuries resulting from falls [8]. Spontaneous sway was predictive of falls but perturbations-induced dynamic sway was not predictive of falls. The spontaneous and the perturbed sways were not correlated or even inversely related $[12,13]$. It was also reported by Hill et al. that many of the falls occur during normal activities such as walking [14].

From the literature survey, a hypothesis is made, i.e. the spontaneous sway would show the age and gender difference related to the fall rates. Though the age and gender differences in static postural sway was reported [15], there has been no investigation on the age and gender differences of the sway during spontaneous dynamic task. Reports available are only the gender difference of the sway during overhead throwing among the elderly subjects [16], and only the age differences in weight-shift and clinical locomotion tasks $[17,18]$. As for the spontaneous dynamic task, 'squat and stand-up' movement task was chosen in the current study. The task is simple and similar to the 'rising from the floor' task whose instability was indicated as a significant risk factor of fall-related injury [8].

The objective of the present study is to investigate the possible influence of age and gender on the dynamic postural sway during squat and stand-up movement. Two-factorial experiment was designed for this investigation, i.e., with the independent factors of gender and age and the dependent variables of dynamic postural sway.

\section{Methods}

\subsection{Subjects}

Participants were 62 numbers of subjects of 60 years old and more (range: 65-86 years) and 62 numbers of young college students (range: 18 - 25years). Ratio of men to women was controlled to be even. Mean age was managed to be comparable between genders. Inclusion criteria were independent walking ability, no disease or injury affecting the dynamic movement. Table 1 shows the demographics. BMI was not different between genders $(\mathrm{p}=0.15)$ and no interaction of gender and age existed $(\mathrm{p}=0.62)$. BFR was higher in women $(\mathrm{p}<0.001)$ throughout age groups, which was shown to be common in Asian populations [19]. Written informed consent was provided by all participants.

Table 1

Participants demographics

\begin{tabular}{|c|c|c|c|c|c|c|c|c|}
\hline \multirow{3}{*}{ Anthropometrics } & \multicolumn{8}{|c|}{ Individual groups } \\
\hline & \multicolumn{2}{|c|}{ Young Male } & \multicolumn{2}{|c|}{ Young Female } & \multicolumn{2}{|c|}{ Elderly Male } & \multicolumn{2}{|c|}{ Elderly Female } \\
\hline & Mean & $(\mathrm{SD})$ & Mean & $(\mathrm{SD})$ & Mean & (SD) & Mean & $(\mathrm{SD})$ \\
\hline Age [years] & 21.1 & $(2.2)$ & 20.3 & $(1.1)$ & 73.2 & $(3.3)$ & 73.4 & $(5.6)$ \\
\hline Height $[\mathrm{cm}]$ & 174.5 & $(5.9)$ & 161.8 & $(4.2)$ & 163.8 & $(5.9)$ & 150.0 & $(5.4)$ \\
\hline Weight $[\mathrm{kg}]$ & 69.0 & $(9.9)$ & 57.9 & $(5.9)$ & 68.5 & $(10.0)$ & 55.3 & $(7.5)$ \\
\hline BMI $\left[\mathrm{kg} / \mathrm{m}^{2}\right]$ & 22.6 & $(2.7)$ & 22.1 & $(2.3)$ & 25.5 & $(2.7)$ & 24.6 & $(2.7)$ \\
\hline BFR [\%] & 19.1 & (4.4) & 26.8 & $(4.7)$ & 28.1 & $(5.0)$ & 37.3 & $(3.7)$ \\
\hline
\end{tabular}



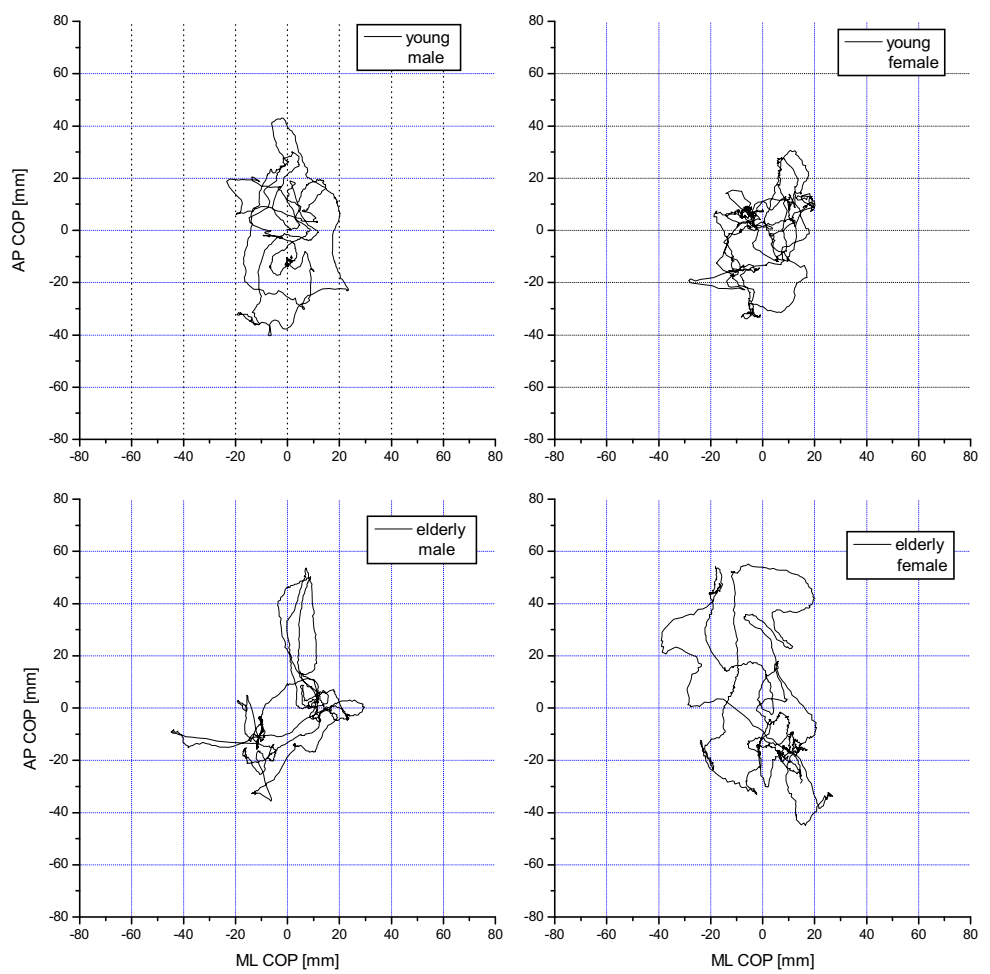

Fig. 1. Representative center of pressure (COP) trajectory in each subject group.

\subsection{Experiments and outcome measures}

Subjects were instructed to squat from initial natural standing posture and consecutively stand-up on a force platform, 2 times in one session and 2 sessions per subject. Trajectory of center of pressure (COP) was measured in anteroposterior (AP) and mediolateral (ML) directions. Absolute COP sway (amplitude) was calculated as the maximal excursion of COP during the task. Relative COP sway was calculated by dividing the COP sway (in $\mathrm{mm}$ ) by the subjects' height (in $\mathrm{m}$ ), [16] to make the dimension of the sway equivalent to the sway angle [20,21]. Outcome measures included the absolute and relative $\mathrm{COP}$ sways, in $\mathrm{AP}$ and $\mathrm{ML}$ directions.

\subsection{Statistical analyses}

2-way ANOVA was performed on the outcome measures (absolute and relative COP sways) with the independent factors of age and gender. If the interaction of the factors is significant, post-hoc analysis was performed by independent t-test. To minimize type II error in the tests, the significance level was decided as $\mathrm{p}<0.05$ without Bonferroni corrections [22]. SPSS (ver. 16) was used for the statistical analyses. 

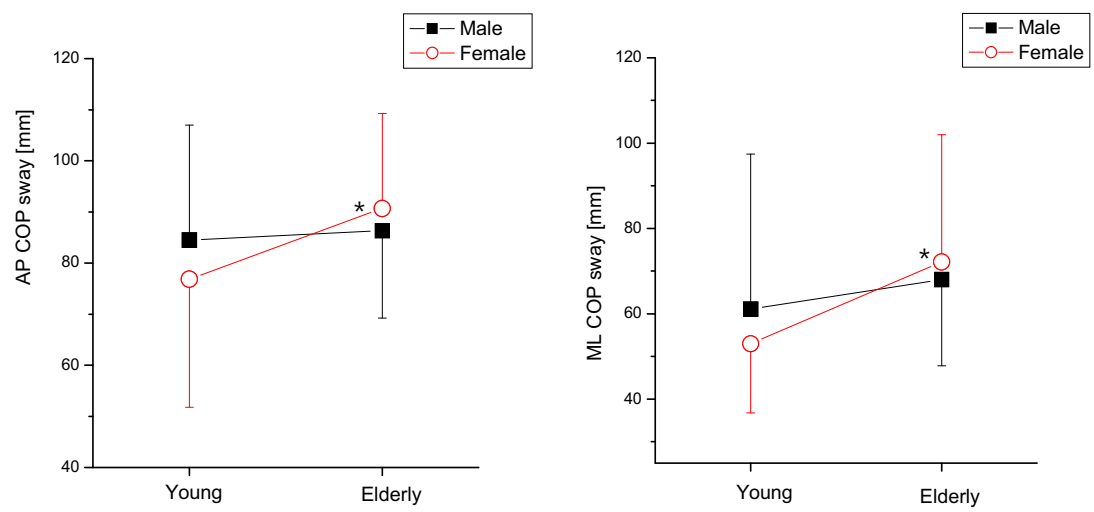

(a) absolute COP sway
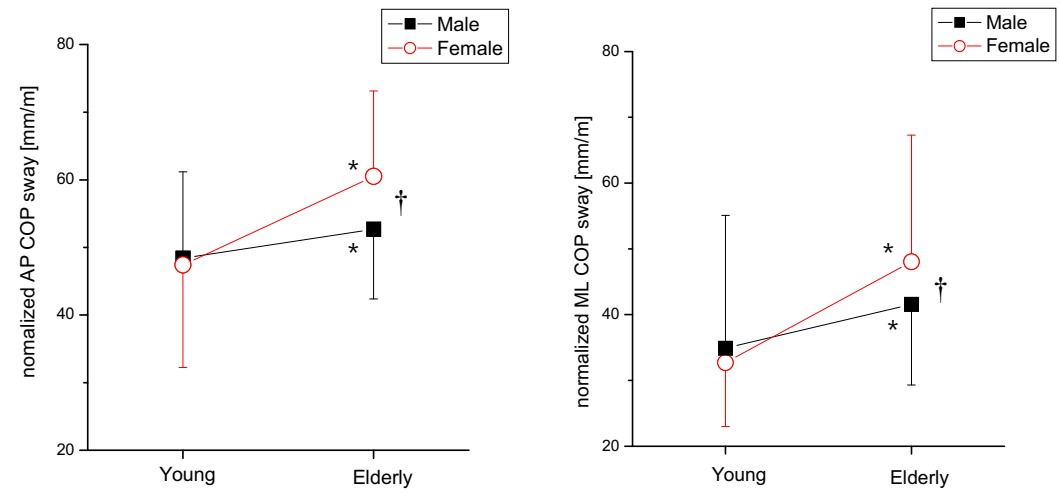

(b) Relative COP sway (normalized by height)

Fig. 2. COP sway in 4 subject groups.

$*$ : significant age-difference (gender-specific), $\uparrow$ : significant gender difference (age-specific)

Table 2

Results of 2-way ANOVA

\begin{tabular}{lllll}
\hline \hline \multirow{2}{*}{$\begin{array}{l}\text { outcome } \\
\text { measures }\end{array}$} & direction & \multicolumn{2}{l}{ main effect } & interaction \\
\cline { 3 - 4 } $\begin{array}{l}\text { COP sway } \\
{[\mathrm{mm}]}\end{array}$ & AP & $* *$ & 0.54 & $*$ \\
\hline $\begin{array}{l}\text { COP sway } \\
\text { normalized } \\
\text { by height } \\
{[\mathrm{mm} / \mathrm{m}]}\end{array}$ & ML & $* * *$ & $*$ & 0.07 \\
\hline $\begin{array}{l}\text { Note: } \\
* p<0.05 ; * * p<0.01 ; * * * p<0.001\end{array}$ & $* * *$ & 0.23 & $*$ \\
\end{tabular}




\section{Results}

Figure 1 shows the representative COP trajectories for the 4 subject groups. The young female showed the smallest COP sway and the elderly female showed the largest sway. Figure 2 shows the absolute and relative COP sways. Table 2 is the result of statistical analysis. Interaction between gender and age was significant for all outcome measures $(p<0.05)$, except for the absolute ML COP sway. Even the absolute ML COP sway showed a tendency of interaction $(\mathrm{p}=0.07)$. Simple main effects are shown in Table 3. Only female showed age-related increase in the absolute COP sway in both directions $(\mathrm{p}<0.01)$. In both genders, relative COP sways (in both directions) increased with age, however, they were different between genders only for the elderly subjects $(\mathrm{p}<0.05)$.

Table 3

Result of post-hoc tests (student $t$ )

\begin{tabular}{|c|c|c|c|c|c|}
\hline \multirow{2}{*}{$\begin{array}{l}\text { outcome } \\
\text { measures }\end{array}$} & \multirow[t]{2}{*}{ direction } & \multicolumn{2}{|c|}{$\begin{array}{l}\text { gender difference } \\
\text { (in each age group) }\end{array}$} & \multicolumn{2}{|c|}{$\begin{array}{l}\text { age difference } \\
\text { (in each gender group) }\end{array}$} \\
\hline & & Young & Elderly & Male & Female \\
\hline \multirow{2}{*}{$\begin{array}{l}\text { COP sway } \\
{[\mathrm{mm}]}\end{array}$} & $\mathrm{AP}$ & 0.08 & 0.18 & 0.61 & $* * *$ \\
\hline & ML & 0.01 & 0.12 & 0.12 & $* *$ \\
\hline $\begin{array}{l}\text { COP sway } \\
\text { normalized }\end{array}$ & AP & 0.69 & $* * *$ & $*$ & $* * *$ \\
\hline $\begin{array}{l}\text { by height } \\
{[\mathrm{mm} / \mathrm{m}]}\end{array}$ & ML & 0.45 & * & $*$ & $* * *$ \\
\hline
\end{tabular}

\section{Discussion and conclusion}

The main finding of this study is that the dynamic postural sway during squat and stand-up movement increases with age only for female, i.e. both in AP and ML directions. When normalized by height, COP sway was greater among elderly females than elderly males, but the sway was similar between genders in the young. This indicates the voluntary dynamic postural control, which was comparable in the young, degrades more rapidly for female than male with the increase in age.

The gender difference in voluntary dynamic postural control observed in this study may be due to any gender difference in sensory, central processing, and musculoskeletal functions. In the absence of accepted gender-related differences in the sensorimotor conduction and processing functions subserving balance, we propose that musculoskeletal factors as the cause of the gender difference in dynamic balance. This hypothesis is supported by the comparable pre-motor time (time duration from external stimulus to the onset of muscle activation) between the elderly genders as well as young genders $[23,24]$.

Candidate features of muscle responsible for the gender difference include the speed and strength of muscle, which determines the muscle quality [25]. Speed of contraction inside muscle can be manifested by the motor time (EMG onset to muscle force onset). Elderly females have longer motor time than elderly males at ankle and hip muscles, but the motor time was similar between genders among the young [23,24]. The number and diameter of fast muscle fibers (myosin heavy chain IIa) were shown to be smaller in elderly females than in elderly males, which were similar between genders 
among the young [26]. Moreover, elderly females, compared to elderly males, were shown to have lower velocity of whole muscle during double leg press [27], and slower reaction to surface perturbation of forward translation [28]. The slower speed of leg muscles may contribute to the worse balance control (due to untimely response to imbalance), and may also be related to the greater COP sway during dynamic squat-and-stand task.

It was also reported that the muscle strength differs between elderly genders. Maximal power of concentric contraction during jumping and the maximal eccentric torque of plantarflexors were lower in the elderly females than in the elderly males [29,30]. The squat-and-stand task of this study includes both concentric and eccentric phases so that smaller strength of both phases in elderly females may have influenced the worse balance during the task.

It is noted that the gender difference in postural sway during static standing was significant only in mediolateral direction [15]. The squat-and-stand task adopted in this study is more difficult task than the quiet standing. It might be that the maximal performance in lower extremity muscles in charge of anterioposterior control was not much important in case of quiet standing, but the role of these muscles became important in more difficult squat-and-stand task.

The occurrence of falls and the associated injury are major public health problems for elderly females. The gender difference in balance during spontaneous dynamic task investigated in this study may be related to the greater fall rate of elderly female, because many of the falls occur during nonthreatening and dynamic activities [14]. Further investigations on the mechanism of the gender difference in dynamic balance are required for the prevention of falls.

\section{Acknowledgement}

This research was supported by National Research Foundation of Korea (NRF) grant funded by the Ministry of Education, Science and Technology (MEST), Korea (No. 2012-025502, 2012-005163).

\section{References}

[1] A.J. Campbell, J. Reinken, B.C. Allan et al., Falls in old age: A study of frequency and related clinical factors, Age Ageing 10 (1981), 264-270.

[2] S. Kojima, T. Furuna, N. Ikeda et al., Falls among community-dwelling elderly people of Hokkaido, Japan, Geriatr. Gerontol. Int. 8 (2008), 272-277.

[3] D. Prudham and J.G. Evans, Factors associated with falls in the elderly: A community study, Age Ageing 10 (1981), 141-146.

[4] K. Aoyagi, P.D. Ross, J.W. Davis et al., Falls among community-dwelling elderly in Japan, J. Bone. Miner. Res. 13 (1998), 1468-1474.

[5] C.Y. Cho and G. Kamen, Detecting balance deficits in frequent fallers using clinical and quantitative evaluation tools, J. Am. Geriatr. Soc. 46 (1998), 426-430.

[6] R.W. Sattin, Falls among older persons: A public health perspective, Annu. Rev. Public. Health. 13 (1992), $489-508$.

[7] A. Bergland, G.B. Jarnlo and K. Laake, Predictors of falls in the elderly by location, Aging. Clin. Exp. Res. 15 (2003), 43-50.

[8] A. Bergland and T.B. Wyller, Risk factors for serious fall related injury in elderly women living at home, Inj. Prev. 10 (2004), 308-313.

[9] L.K. Boulgarides, S.M. McGinty, J.A. Willett et al., Use of clinical and impairment-based tests to predict falls by community-dwelling older adults, Phys. Ther. 83 (2003), 328-339.

[10] V.S. Stel, J.H. Smit, S.M. Pluijm et al., Balance and mobility performance as treatable risk factors for recurrent falling in older persons, J. Clin. Epidemiol. 56 (2003), 659-668. 
[11] T.C. Sell, An examination, correlation, and comparison of static and dynamic measures of postural stability in healthy, physically active adults, Phys. Ther. Sport 13 (2011), 80-86.

[12] B.E. Maki, P.J. Holliday and G.R. Fernie, Aging and postural control, a comparison of spontaneous-and induced-sway balance tests, J. Am. Geriatr. Soc. 38 (1990), 1-9.

[13] M. Piirtola and P. Era, Force platform measurements as predictors of falls among older people-a review, Gerontology 52 (2006), 1-16.

[14] K. Hill, J. Schwarz, L. Flicker et al., Falls among healthy, community-dwelling, older women: A prospective study of frequency, circumstances, consequences and prediction accuracy, Aust. N. Z. J. Public Health 23 (1999), 41-48.

[15] J.W. Kim, G.M. Eom, C.S. Kim et al., Sex differences in the postural sway characteristics of young and elderly subjects during quiet natural standing, Geriatr. Gerontol. Int. 10 (2010), 191-198.

[16] T. LaPier, S. Liddle and C. Bain, A comparison of static and dynamic standing balance in older men versus women, Phyiotherapy Canada, 1997, 207-213.

[17] M.Y. Liaw, C.L. Chen, Y.C. Pei et al., Comparison of the static and dynamic balance performance in young, middleaged, and elderly healthy people, Chang Gung Med. J. 32 (2009), 297-304.

[18] T.M. Steffen, T.A. Hacker and L. Mollinger, Age-and gender-related test performance in community-dwelling elderly people: Six-minute walk test, berg balance scale, timed up \& go test, and gait speeds, Phys. Ther. 82 (2002), 128-137.

[19] D. Zhao, Y. Li, L. Zheng et al., Brief communication: Body mass index, body adiposity index, and percent body fat in asians, American Journal of Physical Anthropology 152 (2013), 294-299.

[20] E.C. Bryant, M.E. Trew, A.M. Bruce et al., Gender differences in balance performance at the time of retirement, Clin. Biomech. (Bristol, Avon) 20 (2005), 330-335.

[21] P. Era, P. Sainio, S. Koskinen et al., Postural balance in a random sample of 7,979 subjects aged 30 years and over, Gerontology 52 (2006), 204-213.

[22] T.V. Perneger, What's wrong with bonferroni adjustments, BMJ 316 (1998), 1236-1238.

[23] J. Hong, J.W. Kim, H.Y. Chung et al., Age-gender differences in the reaction times of ankle muscles, Geriatr. Gerontol. Int. 14 (2013), 94-99.

[24] J.W. Kim, Y. Kwon, H.Y. Chung et al., Age-sex differences in the hip abductor muscle properties, Geriatr. Gerontol Int. 11 (2011), 333-340.

[25] D.W. Russ, K. Gregg-Cornell, M.J. Conaway et al., Evolving concepts on the age-related changes in "muscle quality", J. Cachexia Sarcopenia Muscle 3 (2012), 95-109.

[26] S. Trappe, P. Gallagher, M. Harber et al., Single muscle fibre contractile properties in young and old men and women, J. Physiol. 552 (2003), 47-58.

[27] L.S. Krivickas, R.A. Fielding, A. Murray et al., Sex differences in single muscle fiber power in older adults, Med. Sci. Sports Exerc. 38 (2006), 57-63.

[28] L. Wolfson, R. Whipple, C.A. Derby et al., Gender differences in the balance of healthy elderly as demonstrated by dynamic posturography, J. Gerontol. 49 (1994), M160-167.

[29] P. Caserotti, P. Aagaard, E.B. Simonsen et al., Contraction-specific differences in maximal muscle power during stretch-shortening cycle movements in elderly males and females, Eur. J. Appl. Physiol. 84 (2001), 206-212.

[30] J.W. Kim, S.W. Kim, K.W. Moon et al., Comparison of the maximum moment of ankle plantarflexors during various isokinetic contractions in the elderly males and females and young males and females, Transactions of the Korean Institute of Electrical Engineers 57 (2008), 1893-1895. 